\title{
nombalina
}

(8)

\section{Anfíbios e répteis}

Autor(es): $\quad$ Rebelo, Rui; Carretero, Miguel; Gonçalves, Helena; Segurado, Pedro;

Sequeira, Fernando; Lopes, Isabel

Publicado por: Imprensa da Universidade de Coimbra

URL

persistente: URI:http://hdl.handle.net/10316.2/45886

DOI: $\quad$ DOI:https://doi.org/10.14195/978-989-26-1624-7_9

Accessed : $\quad$ 26-Apr-2023 16:02:47

A navegação consulta e descarregamento dos títulos inseridos nas Bibliotecas Digitais UC Digitalis, UC Pombalina e UC Impactum, pressupõem a aceitação plena e sem reservas dos Termos e Condições de Uso destas Bibliotecas Digitais, disponíveis em https://digitalis.uc.pt/pt-pt/termos.

Conforme exposto nos referidos Termos e Condições de Uso, o descarregamento de títulos de acesso restrito requer uma licença válida de autorização devendo o utilizador aceder ao(s) documento(s) a partir de um endereço de IP da instituição detentora da supramencionada licença.

Ao utilizador é apenas permitido o descarregamento para uso pessoal, pelo que o emprego do(s) título(s) descarregado(s) para outro fim, designadamente comercial, carece de autorização do respetivo autor ou editor da obra.

Na medida em que todas as obras da UC Digitalis se encontram protegidas pelo Código do Direito de Autor e Direitos Conexos e demais legislação aplicável, toda a cópia, parcial ou total, deste documento, nos casos em que é legalmente admitida, deverá conter ou fazer-se acompanhar por este aviso. 
MARIA JOÃO FEIO

VERÓNICA FERREIRA

(EDS.)

\section{IMPRENSA DA \\ UNIVERSIDADE \\ DE COIMBRA \\ COIMBRA \\ UNIVERSITY \\ PRESS}

\section{RIOS DE PORTUGAL COMUNIDADES, PROCESSOS E ALTERAÇÕES}




\section{CA P ÍT U L O 9}

\section{ANFÍBIOS E RÉPTEIS}

\section{Rui Rebelo' ${ }^{1}$, Miguel Carretero², Helena Gonçalves ${ }^{3}$, Pedro Segurado ${ }^{4}$, Fernando Sequeira ${ }^{5} \&$ Isabel Lopes $^{6}$}

\footnotetext{
${ }^{1}$ Departamento de Biologia Animal/Centre for Ecology, Evolution and Environmental Changes, Faculdade de Ciências da Universidade de Lisboa, Portugal, rmrebelo@fc.ul.pt

${ }^{2}$ InBIO-CIBIO, Centro de Investigação em Biodiversidade e Recursos Genéticos, Universidade do Porto, Portugal, carretero@cibio.up.pt 3InBIO-CIBIO - Centro de Investigação em Biodiversidade e Recursos Genéticos, Universidade do Porto, Portugal e MHNC-UP - Museu de História Natural e da Ciência, Universidade do Porto, Portugal, hgoncalves@cibio.up.pt ${ }^{4}$ Centro de Estudos Florestais, Instituto Superior de Agronomia, Universidade de Lisboa, Portugal psegurado@isa.ulisboa.pt 5InBIO-CIBIO, Centro de Investigação em Biodiversidade e Recursos Genéticos, Universidade do Porto, Portugal, fjgsequeira@gmail.com ${ }^{6}$ CESAM - Centro de Estudos de Ambiente e do Mar \& Departamento de Biologia, Universidade de Aveiro, Portugal, ilopes@ua.pt
}

Resumo: Os ribeiros e rios de Portugal albergam espécies de anfíbios e de répteis aquáticos que se adaptaram à reprodução e vida em águas correntes e, em alguns casos, à predação pelos peixes, os principais predadores destes ecossistemas. O número de espécies é relativamente reduzido ( $40 \%$ e $20 \%$, respectivamente, das espécies de anfíbios e de répteis que podem ser encontradas em território nacional), mas inclui algumas das espécies mais icónicas e ameaçadas em Portugal, como a salamandra-lusitânica (Chioglossa lusitanica) e o cágado-de-carapaça-estriada (Emys orbicularis). Neste capítulo 
descrevemos a distribuição, biologia e ameaças a que estão sujeitas estas espécies, organizadas em três grandes grupos - as comunidades de ribeiros de montanha, de ribeiros de planície e de grandes rios. São também referidas duas espécies exóticas que recentemente estabeleceram populações invasoras em alguns dos rios de Portugal.

Palavras-chave: conservação, corrente, espécies invasoras, poluição, predação,

\section{A herpetofauna dos rios e ribeiros de Portugal}

Os anfíbios e os répteis são dois grupos de vertebrados distintos, mas são muitas vezes referidos em conjunto como herpetofauna. Entre as características biológicas que os distinguem, a mais importante é a maior dependência dos anfíbios pelo meio aquático. A maioria dos anfíbios (incluindo todas as espécies que ocorrem em Portugal) só se reproduz em ambientes aquáticos, pois os seus ovos desidratam muito rapidamente se expostos ao ar. Do ovo nasce uma larva (a que se chama girino no caso dos Anuros - rãs, sapos e relas), que tem um período de vida aquática durante o qual respira por brânquias. No final deste período, durante a metamorfose, a larva transforma-se numa miniatura do adulto e sai para terra. Os anfíbios adultos vivem principalmente em terra, se bem que muitas vezes na imediata vizinhança de ambientes húmidos, e de um modo geral visitam a água apenas para a reprodução. No entanto, há algumas espécies que passam a maior parte (ou mesmo toda) a vida adulta na água, aparecendo poucas vezes à superfície ou em terra.

Os répteis são caracterizados pela sua pele impermeável e pela postura de ovos de casca dura, resistente à desidratação, dentro dos quais se desenvolvem embriões que eclodem já como minia- 
turas dos adultos. Podem assim realizar as suas posturas em terra, tornando-se independentes dos ambientes aquáticos. Alguns répteis readquiriram um modo de vida aquático, mas quase todos precisam de voltar a terra para depositar os ovos. Atualmente, apenas algumas espécies de cobras vivíparas (nenhuma delas existente em Portugal) têm uma vida exclusivamente aquática.

A maioria das espécies de anfíbios e de répteis aquáticos da Europa vive associada a ambientes de água parada (lênticos) e não de água corrente (lóticos). A principal razão para este padrão poderá ser o maior perigo de predação que existe nos rios, principalmente por grandes peixes. Em comparação, muito dos pequenos lagos e praticamente todos os charcos temporários têm muito pouco ou nenhum peixe. No caso dos anfíbios que tentam reproduzir-se em rios, o pequeno tamanho das larvas leva também a que sejam facilmente arrastados pela corrente para locais a jusante, onde a ictiofauna constitui um perigo maior. Assim, em Portugal o elenco de espécies da herpetofauna que pode ser encontrado nos rios e ribeiros é reduzido: 9 das 22 espécies de anfíbios e 6 das 30 espécies de répteis registadas para o território continental. Há espécies que podem ser encontradas tanto em ambientes lóticos como lênticos; o critério para a sua inclusão neste capítulo foi a importância relativa dos dois tipos de ambiente (maior nos lóticos) para a manutenção das suas populações. Estas espécies desenvolveram algumas adaptações interessantes à vida em rios e em alguns locais podem ser os vertebrados mais abundantes.

A orografia de Portugal continental e a distribuição assimétrica das chuvas dividem naturalmente o território em duas regiões bioclimáticas. A primeira, a norte da bacia do rio Tejo, inclui $95 \%$ do terreno acima de $400 \mathrm{~m}$ e está sujeita a um clima com influências atlânticas, com temperaturas em geral mais baixas e maior pluviosidade que as zonas a sul. A segunda região, da bacia do Tejo para sul, é mais plana e menos chuvosa. Aqui o clima é mediterrânico, com temperaturas muito elevadas no Verão e menor pluviosidade. 
Há algumas exceções a este padrão, como as serras de S. Mamede e de Monchique, no Sul, que correspondem a ilhas bioclimáticas atlânticas numa paisagem mediterrânica, ou como partes do vale do Douro e de alguns dos seus afluentes, no norte, onde a pluviosidade pode ser tão baixa como nas regiões semi-áridas do Sudeste.

A herpetofauna nacional inclui espécies associadas apenas a cada uma destas regiões bioclimáticas, formando comunidades herpetológicas características, mas há também espécies que ocorrem por todo o território. Para este capítulo, as comunidades herpetológicas foram abordadas de acordo com as suas afinidades bioclimáticas e com a capacidade de suportar a predação por peixes, que restringe algumas espécies às zonas de cabeceira das bacias hidrográficas, enquanto permite a outras a ocorrência em praticamente todos os tipos de curso de água. Assim, serão descritas as comunidades herpetológicas dos: i) ribeiros de montanha, localizados principalmente na região a norte da bacia do Tejo; ii) ribeiros de planície, localizados principalmente na região a sul desta bacia; e iii) rios de todo o território.

\section{Ribeiros de montanha}

Os ribeiros de montanha são caracterizados pela elevada qualidade das suas águas, bem oxigenadas e geralmente oligotróficas. Pelo facto de se situarem ao longo de declives acentuados constituem barreiras à subida de várias espécies de peixes e de lagostins exóticos que predam sobre as posturas e formas larvares de anfíbios. As espécies que beneficiam desta proteção tiveram no entanto de desenvolver modos de evitar que os ovos e larvas sejam arrastados pela corrente. Nestes ribeiros estabeleceu-se uma comunidade de anfíbios característica, considerada indicadora de ambientes aquáticos de boa qualidade e que inclui algumas das espécies mais carismáticas de Portugal, como a salamandra-lusitânica (Chioglossa 
lusitanica) ou a rã-ibérica (Rana iberica). Um ribeiro de montanha no noroeste do país pode manter também populações do sapo-parteiro-comum (Alytes obstetricans) e a única espécie de lagarto existente em Portugal com afinidade por vegetação ribeirinha - o lagarto-de-água (Lacerta schreiberi). Outros anfíbios e répteis ocorrem também nestes ribeiros, mas atingem maiores abundâncias nos cursos de água de zonas mais planas.

\subsection{Salamandra-lusitânica (Chioglossa lusitanica)}

A salamandra-lusitânica (Figura 9.1a), descrita em 1864 pelo naturalista português J. V. Bocage, é uma espécie endémica da região noroeste da Península Ibérica. É uma das espécies mais emblemáticas da nossa fauna devido a características biológicas e morfológicas únicas entre os anfíbios ibéricos, como por exemplo a ausência de pulmões funcionais, possuindo uma respiração essencialmente cutânea e bucofaríngea. Em Portugal apresenta uma distribuição quase contínua nas regiões noroeste e centro/oeste. Ocorre também numa pequena zona da Serra de Sintra, onde persiste desde a sua introdução em 1943.

Apesar de ocorrer, preferencialmente, em áreas de bosque caducifólio, não é raro encontrarem-se exemplares desta espécie junto a cursos de água situados em zonas agrícolas ou até em plantações de espécies florestais. A época de reprodução ocorre entre Maio e Novembro. As posturas são compostas em média por 18 ovos, que ficam presos às paredes rochosas de pequenas cavidades formadas pelas pedras do ribeiro ou em paredes de grutas ${ }^{1}$. O desenvolvimento larvar, que pode durar entre 1 a 2 anos, ocorre sobretudo nas zonas de remanso dos ribeiros ${ }^{2}$. Aí, as larvas podem ser o maior predador residente, alimentando-se de pequenos organismos aquáticos. Os adultos vivem em terra, geralmente perto dos ribeiros, onde se alimentam de pequenos invertebrados, como insetos, aracnídeos e moluscos. 

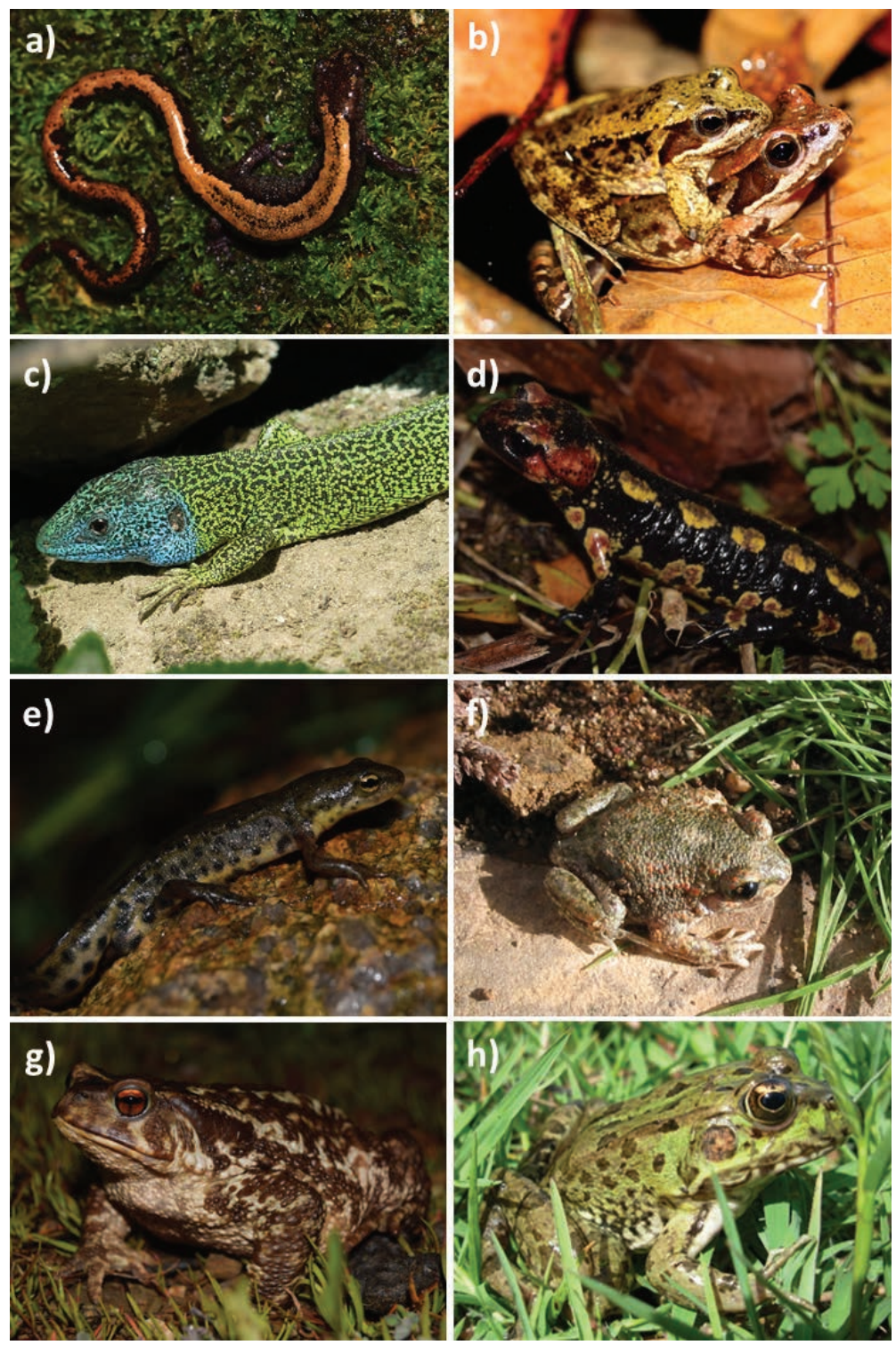

Figura 9.1. Herpetofauna nacional: a) salamandra-lusitânica (Chioglossa lusitanica); b) casal de rã-ibérica (Rana iberica) em amplexo; c) macho de lagarto-de-água (Lacerta schreiberi); d) salamandra-de-pintas-amarelas ( $\mathrm{Sa}$ lamandra salamandra); e) macho de tritão-de-ventre-laranja (Lissotriton boscai); f) sapo-parteiro-ibérico (Alytes cisternasii); g) sapo-comum (Bufo spinosus); h) rã-verde (Pelophylax perezi). Fotografias: a, d, e, g: Francisco Aguilar; b: Guillermo Velo-Antón; c, h: Pedro Segurado; f: Rui Rebelo. 


\subsection{Rã-ibérica (Rana iberica)}

A rã-ibérica (Figura 9.1b) é também endémica do noroeste da Península Ibérica e está presente de forma praticamente contínua em todas as bacias hidrográficas a norte do rio Tejo, encontrando-se ausente ao longo de uma extensa faixa fronteiriça, que inclui o Planalto Mirandês, grande parte dos vales do Douro superior, Côa e Águeda Internacional. No litoral, a sul de Espinho apresenta uma distribuição fragmentada, tendo como limite sul da distribuição o isolado populacional de S. Pedro de Moel. A sul do rio Tejo, apenas ocorre na ilha bioclimática que é a Serra de S. Mamede.

É típica de zonas montanhosas e muito dependente da água, ocorrendo junto a ribeiros de água corrente com vegetação abundante nas margens. Está ativa durante todo o ano e o período reprodutor estende-se de Novembro a Março, variando com a altitude. As posturas são relativamente pequenas, com cerca de 100 a 450 ovos. A fêmea deposita estes ovos em massas esféricas em zonas de remanso de ribeiros, aderentes à vegetação aquática, às pedras ou no fundo lamacento de poças. Em 2013, descobriu-se que se reproduz em grutas subterrâneas na Serra da Estrela ${ }^{3}$. O desenvolvimento larvar dura cerca de 3 meses e os girinos têm caudas fortes que lhes permitem contrariar a corrente. A dieta dos girinos ainda não foi estudada, e poderá ser principalmente de origem vegetal, tal como acontece com outros anuros. Os adultos são terrestres, alimentando-se de pequenos invertebrados, tais como aranhas, larvas de insetos, caracóis e escaravelhos.

\subsection{Sapo-parteiro-comum (Alytes obstetricans)}

Distribui-se por toda a Europa Ocidental, de Portugal até à Alemanha. Em Portugal apresenta uma distribuição praticamente contínua em toda a região norte e centro do país até ao rio Tejo. 
Na faixa litoral a sul do Baixo Vouga a distribuição é pontual e fragmentada ocorrendo apenas em alguns ribeiros costeiros. A sul do rio Tejo está presente unicamente na Serra de S. Mamede. Recentemente. foi revelada a existência de uma elevada diferenciação morfológica e genética das suas populações, indicando a presença de duas linhagens distintas em Portugal - uma ocupando toda a região a norte do rio Douro e a outra distribuindo-se a sul deste rio ${ }^{4}$.

Surge associado a massas de água permanente, quer lóticas, como ribeiros, quer lênticas, como charcos, tanques e lagos de montanha, que lhe possibilitam o prolongado desenvolvimento larvar. A reprodução tem início no final do Inverno ou, nas regiões mais frias, no início da Primavera, altura em que os machos começam a cantar perto dos seus refúgios. Após o acasalamento, que ocorre normalmente em terra, o macho transporta os ovos enrolados nas patas traseiras durante um ou dois meses, até à eclosão dos girinos. Nessa altura, o macho desloca-se até à água, onde permanece até que todos os ovos tenham eclodido. Esta estratégia reprodutora tem duas vantagens: evita a predação das posturas e produz girinos que nascem com um tamanho relativamente grande e boa capacidade de natação ${ }^{5}$, o que lhes permite contrariar a corrente. A duração do período larvar é variável, cerca de 2 a 3 meses, podendo permanecer na água até à Primavera seguinte. Em zonas de alta montanha o período larvar pode prolongar-se por vários anos. As populações são relativamente abundantes, distribuindo-se em pequenas colónias em torno dos locais de reprodução. Os girinos alimentam-se de matéria vegetal e invertebrados aquáticos e os adultos de insetos e moluscos.

\subsection{Lagarto-de-água (Lacerta schreiberi)}

O lagarto-de-água (Figura 9.1c) é uma espécie de lagarto endémico da região noroeste da Península. Em Portugal tem uma distribuição 
contínua desde o Minho até à região de Leiria, e com mais interrupções até à serra de Sintra. A Sul do Tejo há isolados populacionais importantes nas serras de S. Mamede, Cercal e Monchique. De norte para sul, a sua associação aos ecossistemas ribeirinhos fica cada vez mais acentuada. Esta é a única espécie de lacertídeo existente em Portugal que tem alguma afinidade com os ambientes húmidos. Ocorre preferencialmente ao longo de linhas de água em regiões com influências atlânticas e a sua presença é tão associada a este tipo de ecossistema que terá estado na origem do nome da espécie. No entanto, pode também ser encontrado longe de água e nas zonas mais chuvosas do norte de Espanha esta associação às zonas mais húmidas não existe.

As posturas consistem em 7 a 24 ovos, que são enterrados em zonas próximas dos ribeiros, supondo-se que serão mais vulneráveis à desidratação que os ovos das outras espécies de lagarto $^{6}$. A incubação dura 2 a 3 meses, durante o Verão, com a maior parte das eclosões dos juvenis a ocorrer no Outono. Como todos os outros lagartos de Portugal continental preda principalmente invertebrados, sobretudo insetos.

\section{Ribeiros de planície}

Em contraste com a montanha, os ribeiros das zonas mais planas têm águas menos oxigenadas e uma presença mais frequente de grandes predadores de anfíbios, tanto nativos como exóticos. Muitos destes ribeiros são intermitentes (secam no Verão), especialmente nas regiões mais quentes do Sul do país. Esta característica acaba por constituir uma vantagem para os anfíbios que aí se reproduzem, porque a seca regular elimina ou reduz fortemente as populações dos grandes predadores. No Alentejo, por exemplo, muitos dos pequenos ribeiros sazonais não têm qualquer espécie de peixe nem de lagostim. Durante a sua curta duração (geralmente entre Novembro e Março), os vertebrados dominantes nestas comunidades aquáticas podem ser anfíbios e répteis. 
O elenco de uma comunidade aquática de um pequeno ribeiro do sul do país pode incluir larvas de salamandra-de-pintas-amarelas (Salamandra salamandra) e tritões-de-ventre-laranja (Lissotriton boscai) como principais predadores residentes. Entre os anuros, os girinos do sapo-parteiro-ibérico podem ser abundantes e espécies mais generalistas, como o sapo-comum e a cobra-de-água-viperina são também mais frequentes aqui do que nos ribeiros de montanha.

\subsection{Salamandra-de-pintas-amarelas (Salamandra salamandra)}

A salamandra-de-pintas-amarelas (Figura 9.1d) é um dos anfíbios com uma das maiores distribuições geográficas na Europa, de Portugal à Roménia. Tem uma história evolutiva complexa, estando descritas mais de doze subespécies. Em Portugal, a subespécie Salamandra salamandra gallaica distribui-se por todo o país exceto na região algarvia e ao longo das serras do sudoeste Alentejano, onde ocorre Salamandra salamandra crespoi. Não existe nas zonas a jusante da bacia do Sado e no Baixo Alentejo central, uma zona que corresponde à separação entre as duas subespécies. É muito plástica quanto ao local de reprodução, podendo utilizar águas paradas ou correntes, tanto naturais como em construções humanas, e suportando mesmo alguma poluição. Reproduz-se assim em ribeiros tanto de montanha como de planície, mas é nestes últimos, em zonas de remanso, que as larvas atingem maiores abundâncias. A reprodução em rios com peixe é bastante rara porque as larvas são vulneráveis à predação ${ }^{7}$.

O sucesso desta espécie pode estar relacionado com o seu modo de reprodução peculiar - as fêmeas são ovovivíparas, ou seja, os ovos desenvolvem-se no seu interior e são depositadas na água 15 a 100 larvas bem desenvolvidas, com boa capacidade natatória logo após o nascimento. Pensa-se que este tipo de reprodução evoluiu como adaptação a uma reprodução em água corrente em 
ecossistemas temperados 7 . O período larvar dura entre 1 a 6 meses e as larvas são carnívoros vorazes, estruturando as comunidades de invertebrados dos corpos de água onde vivem ${ }^{8}$. Podem também predar larvas de outros anfíbios ou até ser canibais.

Os adultos são terrestres e ocorrem com abundâncias muito elevadas (até 400 exemplares por ha) 9 em zonas de bosque caducifólio, onde podem ser o vertebrado mais abundante. Nas regiões do sul estão mais confinadas à proximidade dos cursos de água. Predam invertebrados do solo que caçam durante a noite, especialmente moluscos, oligoquetas e artrópodes.

\subsection{Tritão-de-ventre-laranja (Lissotriton boscai)}

Os tritões constituem um dos grupos de anfíbios europeus com mais espécies e até recentemente eram englobadas no único género Triturus. Em Portugal continental ocorrem 3 (possivelmente 4) espécies de tritão, mas só o tritão-de-ventre-laranja (Figura 9.1e) pode ser encontrado com regularidade em cursos de água. É uma espécie generalista que pode ser encontrada por todo o país. Também para esta espécie o vale do Sado e o Baixo Alentejo central são uma barreira que separa as populações do sudoeste alentejano e do Algarve (possivelmente uma nova subespécie).

É mais aquático que a salamandra-de-pintas-amarelas e os adultos podem permanecer na água durante grande parte do ano (e até todo o ano em algumas situações especiais, como em tanques ou minas de água). No entanto, é mais normal que a fase da vida adulta seja passada em terra, durante a qual os adultos se podem afastar muito das zonas húmidas.

Pode reproduzir-se tanto em águas paradas como correntes, parecendo preferir locais com água pouco turva. As fêmeas depositam os seus 100 a 150 ovos um a um, e cada um deles aderente à vegetação 
aquática ou às pedras do fundo dos rios. A duração do período larvar é muito variável. As larvas são carnívoras, mas o seu reduzido tamanho torna-as vulneráveis à predação por outros caudados (salamandras e tritões), como larvas de salamandras-de-pintas-amarelas ou até de adultos da própria espécie. Os adultos são predadores aquáticos importantes de invertebrados e na fase terrestre predam artrópodes e moluscos.

\subsection{Sapo-parteiro-ibérico (Alytes cisternasii)}

O sapo-parteiro-ibérico (Figura 9.1f) é uma espécie tipicamente escavadora que apresenta uma série de adaptações morfológicas às planícies áridas do sul da Península Ibérica, onde ocorre associada aos pequenos ribeiros temporários. Trata-se de uma espécie endémica do centro e sudoeste da Península Ibérica, distribuindo-se por grande parte das bacias hidrográficas dos rios Guadiana, Tejo e Douro, com uma distribuição em Portugal praticamente contínua a sul do rio Tejo. A norte distribui-se ao longo da fronteira até ao extremo leste do Parque Natural de Montesinho, ocupando preferencialmente zonas de baixa a média altitude. Tem hábitos fossadores, ocorrendo em zonas de solos arenosos e pouco consistentes, normalmente em regiões abertas e planas. Surge associada a bosques esclerófitos e montados de sobro e azinheira, podendo também ocorrer em pinhais e zonas agrícolas.

A reprodução ocorre no Outono e na Primavera. Nestes períodos os machos cantam durante a noite. Após a fecundação, os machos enrolam os cordões com até 60 ovos em redor dos membros posteriores. Após três semanas, deslocam-se até um ponto de água (tipicamente pequenos ribeiros) e os ovos eclodem sincronizadamente. As larvas completam a metamorfose em 3-5 meses e vivem principalmente em zonas de remansos. Têm uma cauda muito forte, que lhes permite contrariar a corrente, assim como fugir a predadores. Com efeito, mostram alguns comportamentos anti-predatórios ${ }^{10}$ e conseguem coexistir com algumas espécies 
de peixe. Alimentam-se de matéria vegetal e pequenos invertebrados aquáticos. A alimentação dos adultos consiste em insetos e aracnídeos.

\subsection{Sapo-comum (Bufo spinosus)}

O sapo-comum (Figura 9.1g) distribui-se desde o noroeste de África à Península Ibérica e Sul de França e foi até há pouco tempo considerada uma subespécie de Bufo bufo, distribuído por toda a Europa ${ }^{11}$. Em Portugal ocorre por todo o país, numa grande variedade de ecossistemas, desde florestas de coníferas e caducifólias, rios, pântanos, dunas, matos, prados, áreas agrícolas e urbanas. É uma espécie generalista e abundante que tolera bem muitas das atividades humanas e é muito frequente em hortas e campos agrícolas.

Os adultos têm hábitos preferencialmente terrestres e atividade noturna. Durante a época da reprodução, que começa ainda no fim do Inverno, o macho vocaliza para atrair as fêmeas. Uma fêmea pode libertar até 12000 ovos por postura, dispostos em fileiras com vários metros de comprimento. Tanto os ovos como os girinos são tóxicos para muitos vertebrados, o que permite a este sapo reproduzir-se em locais com muito mais predadores do que as outas espécies de anfíbios existentes em Portugal, incluindo grandes rios e barragens ${ }^{12}$. No entanto, parece preferir rios pequenos. Os girinos são pequenos, muito escuros e relativamente lentos, nadando em pequenos cardumes durante 3 a 6 meses (ou ainda mais, no caso de populações de montanha). São principalmente herbívoros e detritívoros, enquanto os adultos são importantes predadores de invertebrados terrestres.

\subsection{Cobra-de-água-viperina (Natrix maura)}

A cobra-de-água-viperina (Figura 9.2a) é a cobra mais comum em Portugal. Ocorre na Península Ibérica e noroeste de África, e tem uma 
distribuição contínua por praticamente todo o território português, podendo ser encontrada em todos os tipos de sistemas aquáticos, quer lóticos, quer lênticos. Está mais associada ao meio aquático que a outra espécie de cobra-de-água (ver secção 4.4.). Está ativa de Março a Outubro (e pontualmente fora destas épocas), reproduzindo-se na Primavera e às vezes também no Outono. As fêmeas põem 4 a 24 ovos, geralmente nas imediações dos corpos de água e a incubação dura de 1 a 3 meses.

Caça pequenos peixes e anfíbios (é um grande predador de girinos), mas também pode comer invertebrados. Raramente ultrapassa 1 metro de comprimento. Este tamanho relativamente pequeno associado à sua abundância faz com que assuma um papel importante nos ecossistemas aquáticos, quer como predador, quer como presa de animais de níveis tróficos superiores, como muitas aves (Capítulo 10) e mamíferos (Capítulo 11).
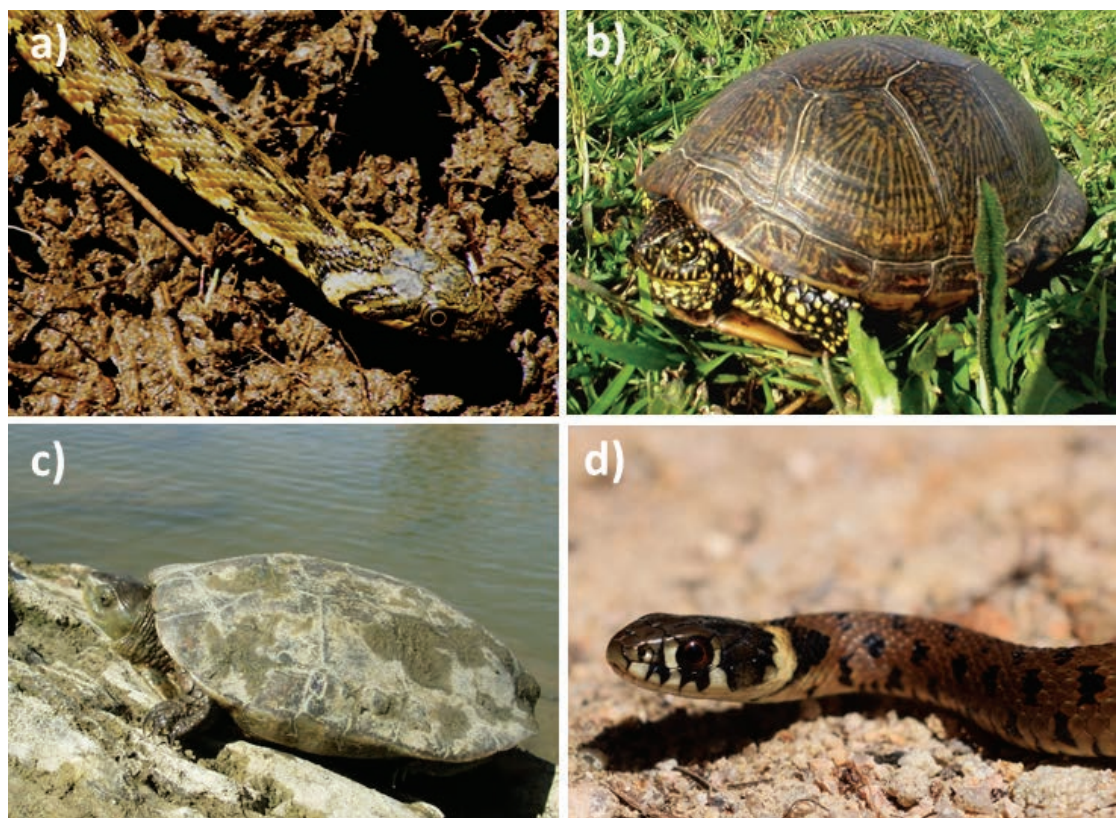

Figura 9.2. Herpetofauna nacional: a) cobra-de-água-viperina Natrix maura;b) cágado-de-carapaça-estriada Emys orbicularis; c) cágado-mediterrânico Mauremys leprosa; d) cobra-de-água-de-colar Natrix astreptophora (juvenil). Fotografias: a: Rui Rebelo; b, c: Pedro Segurado; d: Francisco Aguilar. 


\section{Rios}

Os rios são ecossistemas complexos que mantêm comunidades ricas de peixes, aves e mamíferos aquáticos. É também ao longo das margens dos rios que se encontram as maiores populações dos répteis aquáticos que existem em Portugal continental - duas espécies de tartarugas de água doce (cágados) e as duas espécies de cobra-de-água. Com uma exceção, nenhum anfíbio mantém populações importantes nos grandes rios. No entanto, esta exceção é a rã-verde (Pelophylax perezi), um dos anfíbios mais abundantes e conspícuos da herpetofauna nacional.

O elenco herpetológico característico de um rio de grande caudal em Portugal inclui a rã-verde, o cágado-mediterrânico (Mauremys leprosa) e a cobra-de-água-viperina (abordada na secção 3.5.). Em alguns rios aparecem também espécies mais raras - o cágado-de-carapaça-estriada e a cobra-de-água-de-colar.

\subsection{Rã-verde (Pelophylax perezi)}

A rã-verde (Figura 9.1h) é endémica da Península Ibérica e do Sul de França; em Portugal distribui-se por todo o continente e foi introduzida em todas as ilhas habitadas dos arquipélagos da Madeira e dos Açores, com exceção de S. Jorge, Graciosa e Corvo. É uma espécie muito abundante e com grande plasticidade ecológica que ocorre em ambientes aquáticos temporários e permanentes, tanto em rios e ribeiros, como em charcos, lameiros, lagos e barragens. Os ambientes terrestres associados a esta rã também são variados, desde florestas a áreas agrícolas, pastagens, e até parques urbanos.

Apesar de possuir capacidade de dispersão em terra, raramente surge muito distante de corpos de água. A época de reprodução ocorre entre Março e Outubro, dependendo da área geográfica e em 
algumas regiões os girinos podem permanecer nos corpos de água durante todo o ano. Os machos vocalizam para atrair as fêmeas, que podem depositar entre 800 a 8000 ovos. Os girinos habitam o fundo dos corpos de água, onde se alimentam maioritariamente de detritos e da camada de algas e bactérias que cresce sobre todas as superfícies subaquáticas. Para conseguirem sobreviver nos perigosos corpos de água permanentes, os girinos possuem um arsenal de respostas comportamentais e morfológicas (alteram a sua própria forma e/ou padrão de pigmentação) que lhes permitem escapar aos predadores ${ }^{13}$. Os adultos são grandes predadores de insetos voadores e constituem uma das presas principais para as cobras-de-água e para muitas aves e mamíferos aquáticos.

\subsection{Cágado-de-carapaça-estriada (Emys orbicularis)}

O cágado-de-carapaça-estriada (Figura 9.2b) é a tartaruga de água doce com a repartição geográfica mais extensa a nível mundial. Distribui-se desde Marrocos e Península Ibérica, a oeste e a sul, até às imediações do Mar de Aral, no Cazaquistão, a este, e à Rússia, a norte. Em Portugal, a sua distribuição é fragmentada, sendo mais frequente nas bacias hidrográficas a sul do rio Tejo, nas imediações da Serra de S. Mamede, na região costeira do Algarve, e no planalto costeiro do sudoeste Alentejano. Na região centro ocorre com alguma frequência na Beira Baixa e na região do oeste. No norte há isolados populacionais no Minho e na região de Boticas, Trás-os-Montes. É uma espécie localmente abundante, mas na grande maioria dos locais onde ocorre, e nomeadamente onde coexiste com a outra espécie nativa de cágado (secção 4.3.), como alguns cursos médios de rios, apresenta sempre abundâncias reduzidas ${ }^{14}$. Ocorre frequentemente em cursos de água de média e pequena dimensão com vegetação aquática abundante e corrente fraca. É também frequente 
em sistemas lênticos e pode ocupar corpos de água artificiais, como valas agrícolas ou pequenos açudes.

De um modo geral, inicia a sua atividade entre finais de Fevereiro e Abril e o período de hibernação começa entre Setembro e Novembro. As cópulas são observadas principalmente em Abril e Maio e as posturas são realizadas de final de Maio a meados de Julho, podendo ocorrer dois períodos de postura durante este período. Os neonatos podem emergir dos ninhos em Setembro ou só em Abril do ano seguinte. É uma espécie com um nicho alimentar amplo e oportunista que pode alternar entre uma dieta carnívora e omnívora entre diferentes locais ou ao longo do ano. Alimenta-se principalmente de macroinvertebrados, peixes e estádios larvares de anfíbios, podendo também alimentar-se de vegetação aquática.

\subsection{Cágado-mediterrânico (Mauremys leprosa)}

O cágado-mediterrânico (Figura 9.2c) ocorre no sudoeste da Europa e noroeste de África. Na Península Ibérica está presente na região de clima predominantemente mediterrânico, ocupando a maioria das zonas húmidas que se localizam abaixo dos $1100 \mathrm{~m}$ de altitude. Em Portugal é uma espécie muito comum no sul, interior centro e terra quente do nordeste. Nas zonas montanhosas do centro de Portugal ocorre com menos frequência e no noroeste a distribuição é muito fragmentada, devido simultaneamente a condições climatéricas menos favoráveis e reduzida disponibilidade de habitat.

É mais abundante em ambientes aquáticos lênticos permanentes com vegetação aquática, mas pode ser observado em quase todo o tipo de ambientes aquáticos. Em comparação com a outra espécie nativa (secção 4.2.), apresenta abundâncias muito superiores e tende a ocupar meios aquáticos mais permanentes e a ocorrer com maior frequência em cursos médios e inferiores de rios e ribeiros ${ }^{15}$. 
O período de atividade anual decorre geralmente entre finais de Fevereiro e Outubro. As cópulas são observadas principalmente na primavera mas, no Sul, um segundo período de cópula pode ocorrer no Outono. No Sul de Espanha, as posturas são realizadas de finais de Maio a meados de Julho e os neonatos emergem em finais de Agosto ${ }^{16}$. Tendo em conta as elevadas abundâncias que atinge nalguns meios aquáticos, constitui certamente um importante elemento nas cadeias tróficas. Alimenta-se principalmente de macroinvertebrados aquáticos, peixes, anfíbios e inclui uma importante componente vegetal na dieta.

\subsection{Cobra-de-água-de-colar (Natrix astreptophora)}

Foi recentemente descoberto que as populações de cobra-de-água-de-colar (Figura 9.2d) da Península Ibérica e provavelmente

do norte de África, anteriormente classificadas como a subespécie Natrix natrix astreptophora, correspondem na verdade a uma espécie diferente da que se encontra a partir da vertente francesa dos Pirinéus ${ }^{17}$. Em Portugal, apesar de ser mais rara que Natrix maura (secção 3.5.), ocorre por todo o território, de uma forma mais contínua nas regiões com influências atlânticas e mais descontínua e com populações menos abundantes nas regiões mediterrânicas do sul.

É mais abundante em águas permanentes, lóticas ou lênticas, onde está ativa de Março a Outubro (ou esporadicamente fora desta época, em dias quentes). Apesar dos hábitos aquáticos, esta cobra também se afasta com frequência dos corpos de água e pode ser encontrada em ambientes terrestres húmidos. A reprodução ocorre na Primavera, podendo haver também acasalamentos no Outono. Os ovos (entre 6 a 70) são postos debaixo de vegetação em decomposição e a incubação dura até 2 meses.

É uma caçadora ativa principalmente de anfíbios, mas também de peixes pequenos. Os juvenis podem caçar invertebrados aquáticos. 
Os adultos podem atingir tamanhos respeitáveis de até 2 metros de comprimento, sendo um dos principais predadores nos rios onde ocorrem. Podem também ser presas importantes para aves e mamíferos.

\section{Ameaças à herpetofauna dos ribeiros e rios de Portugal}

De um modo geral, as ameaças às espécies de répteis e anfíbios dos cursos de água aumentam com a proximidade às áreas mais povoadas, e são por isso maiores em zonas mais planas e onde os rios têm maior caudal. Nas montanhas a própria inacessibilidade do terreno protege muitos cursos de água das ações com maior impacto, como a extração de água ou a contaminação química. Nestas regiões uma das ações com maiores impactos na herpetofauna é a plantação de monoculturas de eucalipto em áreas extensas, que diminui a disponibilidade e qualidade do habitat, provocando um confinamento dos indivíduos às margens dos cursos de água e um empobrecimento na disponibilidade de presas. Por exemplo, um estudo recente baseado em dados recolhidos ao longo de 40 anos numa população de salamandra-lusitânica, que vive ao longo de um pequeno ribeiro situada numa plantação de eucaliptos na serra de Santa Justa, a sul de Valongo, mostrou uma diminuição muito significativa no tamanho da população, que decresceu de um total de 1500 exemplares para menos de $50^{18}$. O corte frequente da vegetação ribeirinha altera também as condições não só do ambiente terrestre onde os répteis e os anfíbios adultos vivem, como também as características da água onde se desenvolvem as formas larvares.

Nas zonas de meia encosta e de planície tornam-se mais importantes as ações que diminuem a qualidade e quantidade de água, devido às modificações dos cursos de água (por encanamento, construção de represas ou mini-hídricas) e ao acréscimo de poluentes, principalmente de origem agrícola, como pesticidas e fertilizantes. 
Também é mais frequente nestes ribeiros a destruição completa das galerias ripárias ou a sua redução a uma faixa muito estreita. A maior ocupação humana das regiões menos declivosas acarreta o desenvolvimento de redes viárias mais densas, o que aumenta o impacto da mortalidade por atropelamento de espécies como a salamandra-comum ou o sapo-comum. Todas estas ações atingem a sua extensão e intensidade máximas nos locais com maior concentração humana.

As águas mais lentas e mais quentes dos ribeiros e rios de planície são também mais facilmente invadidas por várias espécies de peixes e lagostins não-nativos ${ }^{12}$ que, com frequência, são predadores eficazes das posturas e larvas dos anfíbios e mesmo de alguns répteis aquáticos.

As populações de sapo-parteiro-comum do Parque Natural da Serra da Estrela sofreram perdas significativas, devido ao surgimento de uma doença infeciosa letal - quitridiomicose - causada pelo fungo Batrachochytrium dendrobatidis ${ }^{19}$. O surgimento de um segundo agente patogénico - um ranavírus - causou ranoviroses letais e um novo declínio destas populações ${ }^{20}$.

\section{Herpetofauna exótica}

A herpetofauna aquática nativa é vulnerável a várias espécies exóticas e algumas destas espécies são também anfíbios ou répteis. Em Portugal continental há pelo menos duas espécies que estabeleceram populações em cursos de água: um anfíbio, a rã-de-unhas-africana (Xenopus laevis), originária da África do Sul ${ }^{21}$; e um réptil, a tartaruga-da-Florida ou de orelha-vermelha (Trachemys scripta $)^{22}$. No entanto, nas suas regiões de origem ambas as espécies são mais comuns em águas paradas, pelo que a colonização de sistemas lóticos em Portugal envolveu uma alteração do seu nicho habitual. Em ambos os casos as invasões aconteceram como 
resultado de libertações de animais na natureza, acidentais (no caso da rã-de-unhas-africana) ou deliberadas (nos múltiplos casos conhecidos de tartaruga-da-Florida).

Nos ribeiros invadidos pela rã-de-unhas-africana, duas pequenas bacias no Concelho de Oeiras, os principais impactos da espécie invasora consistirão na competição por recursos alimentares com as espécies nativas de peixes de água doce 23 , e um programa de controlo e erradicação em curso tem demonstrado resultados promissores ${ }^{24}$.

Já a tartaruga-da-Florida ou de orelha-vermelha tem as suas maiores populações invasoras nos sistemas lagunares do sul do país. Contudo, algumas zonas húmidas, onde se detetou a presença da espécie, estão associadas a cursos de água, como é o caso dos pauis da Tornada e do Boquilobo e da Ria Formosa. É muito provável que a espécie se disperse através dos cursos de água. Apesar do seu real impacto nos ecossistemas nunca ter sido verdadeiramente testado, a tartaruga-da-Florida ou de orelha-vermelha é frequentemente considerada como uma ameaça às tartarugas de água doce nativas, uma vez que poderá competir por alimento, locais de termorregulação e locais de postura ${ }^{25}$. É também considerada um vetor de parasitas e outros agentes patogénicos, como a Salmonella spp. ${ }^{26}$. Também esta espécie foi o objeto de um programa de erradicação, que decorreu no Parque Natural da Ria Formosa em 2011 e 2012, tendo sido capturadas 214 tartarugas exóticas de várias espécies ${ }^{27}$.

Apesar dos esforços, a rã-de-unhas-africana ainda é vendida em lojas de animais de estimação, pelo que continua a existir o risco de libertações na natureza. A implementação em Portugal do Decreto-Lei n $565 / 99$ de 21 de Dezembro interditou a criação ou detenção em local confinado e a utilização como animal de companhia de todas as subespécies de Trachemys scripta. No entanto, desde a restrição imposta à importação de espécies do género Trachemys, outras espécies de tartarugas exóticas têm vindo a satisfazer a procura crescente por este grupo de animais. Em Portugal, estima-se que 
entre 2003 e 2007 foram importadas cerca de 470 mil tartarugas de água doce, entre as quais as espécies do género Pseudemys e Graptemys representaram cerca de $85 \%$ do total de indivíduos ${ }^{28}$. O comércio de tartarugas do género Trachemys, nomeadamente das subespécies T. scripta scripta ou T. scripta troostii, ainda existe em muitos espaços comerciais sendo estas espécies frequentemente vendidas como $P$. concinna ${ }^{29}$. Segundo Masin et al. ${ }^{30}$, as espécies P. concinna e G. pseudogeographica apresentam um baixo risco de invasão em Portugal, mas já foram observados indivíduos das duas espécies em ecossistemas aquáticos naturais ou semi-naturais, como por exemplo na região oeste e no Algarve ${ }^{27}$.

\section{Herpetofauna como bioindicador}

Os anfíbios e répteis aquáticos têm diferentes suscetibilidades à contaminação dos meios aquáticos. As espécies mais sensíveis desaparecem rapidamente dos locais perturbados, pelo que a sua presença é tomada como indicação de um bom estado de conservação. Só as espécies mais resistentes à contaminação (e por isso mais comuns) é que têm sido utilizadas em estudos ecotoxicológicos.

Entre os anfíbios há espécies com elevada sensibilidade ecológica, que dependem de uma boa qualidade de água, como a salamandra-lusitânica e a rã-ibérica ${ }^{1}$. Ambas são observadas frequentemente em cursos de águas límpidas e correntes, sem aparentes focos de poluição, pelo que poderão ser consideradas bioindicadoras da qualidade da água. Do mesmo modo, apesar do cágado-de-carapaça-estriada não fazer parte de programas de biomonitorização para a avaliação da qualidade ecológica de ambientes aquáticos (p.ex., no âmbito da implementação da Diretiva Quadro da Água), possui alguns requisitos ecológicos que o tornam um potencial indicador de qualidade biótica. Por um lado apresenta um padrão de utilização de habitats e 
micro-habitats complexo, com preferências que variam quer ao longo da vida quer ao longo do ano ${ }^{31}$. É por isso dependente de alguma heterogeneidade ambiental e, como tal, sensível a alterações hidromorfológicas dos meios aquáticos. Por outro lado há trabalhos que indicam um efeito negativo da poluição na ocorrência da espécie ${ }^{32}$.

Entre as espécies para as quais há mais informação relativamente à sua sensibilidade à contaminação destacamos quatro espécies de anfíbios e três de répteis:

\section{Anfíbios}

Tritão-de-ventre-laranja

A diminuição do $\mathrm{pH}$ da água leva à alteração (até ao extremo da anulação) dos comportamentos reprodutores deste tritão, possivelmente por interferência com a capacidade de perceção dos estímulos químicos emitidos pelos animais 33 . Provavelmente a acidificação da água perturbará também a oviposição por parte das fêmeas, tal como acontece com outra espécie de tritão $\mathrm{O}^{34}$. O desenvolvimento embrionário e o crescimento das larvas após a eclosão é comprometido, quer por efeito de nitratos, quer por efeito de amónia/acidificação da água ${ }^{35}$. Após a metamorfose e passagem para o meio terrestre o nitrato de amónio pode causar problemas respiratórios e a morte rápida dos indivíduos ${ }^{36}$. Todos os estádios do ciclo de vida são assim afetados, e podemos suspeitar que o mesmo se passará com outras espécies de caudados que ainda não foram testadas.

\section{Salamandra-de-pintas-amarelas}

Tolera muitas das atividades humanas e até mantém populações em parques urbanos. Não houve até agora estudos sobre os impactos dos poluentes nesta espécie. No entanto, na Holanda foi apontada a coincidência de altas concentrações de nitratos com o declínio de populações locais ${ }^{37}$, e em Itália foi mostrado que tende a evitar águas com maior concentração de fosfatos ${ }^{38}$. 


\section{Sapo-comum}

Foram identificadas várias ameaças para esta espécie relacionadas com poluição química. Montori et al. ${ }^{39}$ identificaram a contaminação com fertilizantes e pesticidas no Delta de Llobregat (Espanha) como responsável pelo declínio das populações locais. Outros autores reportaram a sensibilidade desta espécie a compostos químicos em laboratório, nomeadamente um efeito negativo de concentrações ambientalmente relevantes de nitrato de amónio na sua sobrevivência, crescimento e desenvolvimento ${ }^{40,41}$.

\section{Rã-verde}

Por não ser muito exigente relativamente à qualidade da água, pode frequentar sistemas aquáticos eutrofizados ou com outro tipo de perturbação, inclusivamente química. Por exemplo, Marques et al. ${ }^{42}$ identificaram adultos em pequenas lagoas de uma mina de urânio no centro de Portugal, e Costa et al. ${ }^{43}$ identificaram populações em locais com salinidades elevadas e com contaminação por drenagem ácida de minas pirítico-cúpricas, no norte e sul de Portugal, respetivamente. Em parte devido a esta tolerância, esta rã constitui um bom bioindicador de contaminação aquática. Burghelea et al. ${ }^{44}$ verificaram que os juvenis desta rã que vivem em arrozais apresentaram um tamanho e massa corporal inferior ao de juvenis que vivem em regiões naturais; Pastor et al. ${ }^{45}$ e Tejedo \& Reques ${ }^{46}$, encontraram nos girinos níveis elevados de alguns organoclorados e de metais pesados e arsénio, respetivamente. Marques et al. ${ }^{47}$ também detetaram níveis elevados de alguns metais (berílio, alumínio, manganês, ferro e urânio) no fígado de adultos que habitam lagoas junto a uma mina de urânio localizada no centro de Portugal, assim como necrose tubular nos rins destes indivíduos ${ }^{48}$. Vários ensaios de laboratório têm revelado a sensibilidade de diferentes estádios de desenvolvimento desta rã a vários poluentes (p.ex., nitrato de amónia, pesticidas, metais, nanomateriais, antibióticos). Os efeitos 
provocados pela exposição a compostos químicos consistem, entre outros, em vários tipos de malformações, diminuição da sobrevivência, redução do crescimento somático e reprodução, alterações no metabolismo ${ }^{49-51}$.

\section{Répteis}

Mingo et al. ${ }^{52}$ estimaram a exposição a pesticidas a que as diferentes espécies de répteis da Europa estão expostas, de acordo com os locais onde vivem e com a sua capacidade de bioacumulação. Espécies maiores e com maiores taxas metabólicas que vivam em locais sujeitos a maior deposição e bioacumulação de poluentes estarão naturalmente mais expostas. Entre as espécies mais expostas está o cágado-mediterrânico. A mesma equipa identificou o lagarto-de-água como espécie vulnerável à acumulação de pesticidas 53 .

A espécie de réptil aquático para a qual há mais informação ecotoxicológica é a cobra-de-água-viperina. Houve um declínio acentuado nos efetivos desta espécie no delta do rio Ebro, em particular nos arrozais, enquanto as populações de ribeiros próximos não sofreram alterações, o que é uma indicação de uma possível relação com a crescente contaminação química associada à produção intensiva de $\operatorname{arroz}^{54}$. Nesta espécie já foi documentada a bioacumulação de compostos organoclorados (PCBs e DDTs), especialmente nos machos, uma vez que as fêmeas perdem regularmente estes compostos ao depositá-los nos ovos ${ }^{55}$.

\section{Outras leituras}

Ferrand de Almeida N., Ferrand de Almeida P., Gonçalves H., Sequeira F., Teixeira J. \& Ferrand de Almeida F. 2001. Guia dos anfíbios e répteis de Portugal. FAPAS \& Câmara Municipal do Porto. Portugal, Porto

Loureiro A., Ferrand de Almeida N., Carretero M.A. \& Paulo O.S. 2008. Atlas dos anfíbios e répteis de Portugal. Instituto da Conservação da Natureza e da Biodiversidade. Portugal, Lisboa 
Pleguezuelos J.M., Márquez R., Lizana M. 2002. Atlas y libro rojo de los anfibios y reptiles de España. Dirección General de la Conservación de la Naturaleza Asociación Herpetologica Española. España, Madrid

Sanz, J.J. 2017. Enciclopedia virtual de los vertebrados Españoles. Museo Nacional de Ciencias Naturales. España, Madrid. http://www.vertebradosibericos.org/

\section{Referências bibliográficas}

${ }^{1}$ Teixeira J., Sequeira F., Alexandrino J. \& Ferrand N. 1999. Bases para a conservação da Salamandra-lusitânica (Chioglossa lusitanica). Estudos de Biologia e Conservação da Natureza. 22. Instituto de Conservação da Natureza (ICN). Portugal, Lisboa

${ }^{2}$ Sequeira F., Ferrand N. \& Crespo E.G. 2003. Reproductive cycle of the golden-striped salamander Chioglossa lusitanica (Caudata, Salamandridae) in NW Portugal. Amphibia-Reptilia 24: 1-12

${ }^{3}$ Rosa G.M. \& Penado A. 2013 Rana iberica (Boulenger, 1879) goes underground: subterranean habitat usage and new insights on natural history. Subt. Biol. 11: $15-29$

${ }^{4}$ Gonçalves H., Maia-Carvalho B., Sousa-Neves T., García-París M., Sequeira F., Ferrand N. \& Martínez-Solano I. 2015. Multilocus phylogeography of the common midwife toad, Alytes obstetricans (Anura, Alytidae): Contrasting patterns of lineage diversification and genetic structure in the Iberian refugium. Mol. Phylogenet. Evol. 93: 363-379

${ }^{5}$ Crespo E.G. 1982. Contribuição para o conhecimento da biologia das espécies ibéricas de Alytes, A. obstetricans boscai, Lataste 1879 e A. cisternasii, Boscá 1879 (Amphibia, Discoglossidae): morfologia dos adultos e dos girinos. Arq. Mus. Bocage. (Sér. C) 1: 255-312

${ }^{6}$ Marco A., Díaz-Paniagua C. \& Hidalgo-Vila J. 2004. Influence of egg aggregation and soil moisture on incubation of flexible-shelled lacertid lizard eggs. Can. J. Zool. 82: 60-65

${ }^{7}$ Thiesmeier B. \& Schuhmacher H. 1990. Causes of larval drift of the fire salamander, Salamandra salamandra terrestris, and its effects on population dynamics. Oecologia 82: 259-263

${ }^{8}$ Blaustein L., Friedman J. \& Fahima T. 1996. Larval Salamandra drive temporary pool community dynamics: evidence from an artificial pool experiment. Oikos 76 : 392-402

${ }^{9}$ Rebelo R., \& Leclair M. H. 2003. Site tenacity in the terrestrial salamandrid Salamandra salamandra. J. Herpetol. 37: 440-445

${ }^{10}$ Nunes A.L., Richter-Boix A., Laurila A. \& Rebelo R. 2013. Do anuran larvae respond behaviourally to chemical cues from an invasive crayfish predator? A communitywide study. Oecologia 171: 115-127

${ }^{11}$ Recuero E., Canestrelli D., Vörös J., Szabó K., Poyarkov N.A., Arntzen J.W., CrnobrnjaIsailovic J., Kidov A.A., Coglăniceanu D., Caputo F.P., Nascetti G. \& Martínez-Solano 
I. 2012. Multilocus spevcies tree analyses resolve the radiation of the widespread Bufo bufo species group (Anura, Bufonidae). Mol. Phylogenet. Evol. 62: 71-86

${ }^{12}$ Cruz M.J., Rebelo R. \& Crespo E.G. 2006. Effects of an introduced crayfish, Procambarus clarkii, on the distribution of south-western Iberian amphibians in their breeding habitats. Ecography 29: 329-338

${ }^{13}$ Nunes A.L., Orizaola G., Laurila A. \& Rebelo R. 2014. Rapid evolution of constitutive and inducible defenses against an invasive predator. Ecology 95: 1520-1530

${ }^{14}$ Segurado P. \& Araújo A.P.R. 2008. Population structure of Emys orbicularis in syntopy and allotopy with Mauremys leprosa. Rev. Esp. Herpetol. 22: 45-54

${ }^{15}$ Segurado P., Kunin W.E., Filipe A.F. \& Araújo M.B. 2012. Patterns of coexistence of two freshwater turtles are affected by spatial scale. Basic Appl. Ecol. 13: 371-379

${ }^{16}$ Keller C. 1997. Ecología de poblaciones de Mauremys leprosa e Emys orbicularis en el Parque Nacional de Doñana. PhD. Thesis. Universidad de Sevilla. Spain, Sevilla

${ }^{17}$ Pokrant F., Kindler C., Ivanov M., Cheylan M., Geniez,P., Böhme W. \& Fritz U. 2016. Integrative taxonomy provides evidence for the species status of the IberoMaghrebian grass snake Natrix astreptophora. Biol. J. Linn. Soc. 118: 873-888

${ }^{18}$ Arntzen J.W. 2015. Drastic population size change in two populations of the golden-striped salamander over a forty-year period-are eucalypt plantations to blame? Diversity 7: 270-294

${ }^{19}$ Rosa G.M., Anza I., Moreira P.L., Conde J., Martins F., Fisher M.C. \& Bosch J. 2013. Evidence of chytrid-mediated population declines in common midwife toad in Serra da Estrela, Portugal. Anim. Conserv. 16: 306-315

${ }^{20}$ Rosa G.M., Sabino-Pinto J., Laurentino T.G., Martel A., Pasmans F, Rebelo R., Griffiths R.A., Stöhr A.C., Marschang R.E., Price S.J., Garner T.W.J. \& Bosch J. 2017. Impact of asynchronous emergence of two lethal pathogens on amphibian assemblages. Sci. Rep.7: 43260

${ }^{21}$ Rebelo R., Amaral P., Bernardes M., Oliveira J., Pinheiro P. \& Leitão D. 2010. Xenopus laevis (Daudin, 1802), a new exotic amphibian in Portugal. Biol. Inv. 12: 3383-3387

${ }^{22}$ Loureiro A., Ferrand de Almeida N., Carretero M.A. \& Paulo O.S. 2008. Atlas dos anfíbios e répteis de Portugal. Instituto da Conservação da Natureza e da Biodiversidade, Lisboa

${ }^{23}$ Marques R. 2016. Impactos tróficos da rã-de-unhas-africana Xenopus laevis na ribeira de Barcarena (Oeiras, Portugal). Tese de Mestrado. Faculdade de Ciências da Universidade de Lisboa. Portugal, Lisboa

${ }^{24}$ Rebelo R., Marques R., Moreira F., Maurício A. \& Sousa M. 2016. Plano de erradicação de Xenopus laevis nas ribeiras do concelho de Oeiras. Relatório Ano VII (2016). cE3c/CMO/ICNF, Portugal, Lisboa

${ }^{25}$ Pearson S.H., Arvey H.W. \& Spotila J.R. 2015. Juvenile invasive red- eared slider turtles negatively impact the growth of native turtles: implications for global freshwater turtle populations. Biol. Conserv. 186: 115-121

${ }^{26}$ Meyer L., Du Preez L., Bonneau E., Héritier L., Quintana M.F., Valdeón A., Sadaoui A., Kechemir-Issad N., Palacios C. \& Verneau O. 2015. Parasite host-switching 
from the invasive American red-eared slider, Trachemys scripta elegans, to the native Mediterranean pond turtle, Mauremys leprosa, in natural environments. Aquat. Inv. 10: 79-91

${ }^{27}$ LIFE-Trachemys 2012. Memoria intermedia de actuaciones. Años 2011-2012. Informes LIFETrachemys $\mathrm{n}^{\circ} 14$. Conselleria d'Infraestructures, Territori i Medi Ambient. España, Madrid

${ }^{28}$ Palma A. 2012. Análise da importação de espécies exóticas. Potenciais impactos nas espécies autóctones. Tese de Mestrado. Faculdade de Ciências da Universidade de Lisboa. Portugal, Lisboa

${ }^{29} \mathrm{Cruz}$ A. 2013. Estudos sobre a capacidade de reprodução de Trachemys scripta e Pseudemys concinna em condições naturais, no Litoral Norte de Portugal. Tese de Mestrado. Universidade de Trás-os-Montes e Alto Douro. Portugal, Vila Real

${ }^{30}$ Masin S., Bonardi A., Padoa-Schioppa E., Bottoni L. \& Ficetola G.F. 2014. Risk of invasion by frequently traded freshwater turtles. Biol. Inv. 16: 217-231

${ }^{31}$ Cadi A., Nemoz M., Thienpont S. \& Joly P. 2008. Annual home range and movement in freshwater turtles: management of the endangered European pond turtle (Emys orbicularis). Rev. Esp. Herpetol. 22: 71-86

${ }^{32}$ Mieza-Paez E., Martínez-Martínez D., Tarragó A., Such Sanz A. \& Nogués Vera J. 2016. Current situation and environmental factors affecting the distribution of Emys orbicularis in Sèquia Major (NE Iberian Peninsula) in syntopy with Mauremys leprosa. Bas. Appl. Herpetol. 30: 47-59

${ }^{33}$ Ortiz-Santaliestra M.E., Marco A., Fernández-Benéitez M.J. \& Lizana, M. 2009. Alteration of courtship behavior because of water acidification and minor effect of ammonium nitrate in the Iberian newt (Lissotriton boscai). Environ. Toxicol. Chem. 28: 1500-1505

${ }^{34}$ Ortiz-Santaliestra M.E., Marco A., Fernández-Benéitez M.J. \& Lizana M. 2007. Effects of ammonium nitrate exposure and water acidification on the dwarf newt: the protective effect of oviposition behaviour on embryonic survival. Aquat. Toxicol. 85: 251-257

${ }^{35}$ Ortiz-Santaliestra M.E., Marco A. \& Lizana, M. 2011. Realistic levels of a fertilizer impair Iberian newt embryonic development. Herpetologica 67: 1-9

${ }^{36}$ Ortiz-Santaliestra M.E., Marco A. \& Lizana M. 2005. Sensitivity and behavior of the Iberian newt, Triturus boscai, under terrestrial exposure to ammonium nitrate. Bull. Environ. Contamin. Toxicol. 75: 662-669

${ }^{37}$ Spitzen-van der Sluijs A., Spikmans F., Bosman W., de Zeeuw M., van der Meij T., Goverse E., Kik M., Pasmans F. \& Martel A. 2013. Rapid enigmatic decline drives the fire salamander (Salamandra salamandra) to the edge of extinction in the Netherlands. Amphibia-Reptilia 34: 233-239

${ }^{38}$ Ficetola G.F., Marziali L., Rossaro B., De Bernardi F. \& Padoa-Schioppa E. 2011. Landscape-stream interactions and habitat conservation for amphibians. Ecol. Appl. 21: 1272-1282

${ }^{39}$ Montori A., Franch M., Llorente G.A., Richter A., Sansebastian O., Garriga N. \& Pascual G. 2009. Declivi de les poblacions d'amfibis al Delta del Llobregat. Materials del Baix Llobregat 15: 65-70

${ }^{40}$ Ortiz-Santaliestra M.E. 2008. Efectos de la contaminación por nitrógeno sobre la reproducción y el desarrollo de anfibios. PhD Thesis, Universidad de Salamanca, España, Salamanca 
${ }^{41}$ García-Muñoz E., Guerrero F., Bicho R.C. \& Parra G. 2011. Effects of ammonium nitrate on larval survival and growth of four Iberian amphibians. Bull. Environ. Contam. Toxicol. 87: 16-20

${ }^{42}$ Marques S.M., Gonçalves F. \& Pereira R. 2008. Effects of a uranium mine effluent in the early-life stages of Rana perezi Seoane. Sci. Tot. Environ. 402: 29-35

${ }^{43}$ Costa S., Lopes I., Proença D.N. \& Morais P.V. 2016. Diversity of cutaneous microbiome of Pelophylax perezi populations inhabiting different environments. Sci. Tot. Environ. 572: 995-1004

${ }^{44}$ Burghelea C.I., Zaharescu D.G. \& Palanca-Soler A. 2013. Phenotypic indicators of developmental instability in an endemic amphibian from an altered landscape (Monegros, NE Spain). Amphibia-Reptilia 34: 505-516

${ }^{45}$ Pastor D., Sanpera C., González-Solís J., Ruiz X. \& Albaigés J. 2004. Factors affecting the organochlorine pollutant load in biota of a rice field ecosystem (Ebro Delta, NE Spain). Chemosphere 55: 567-576

${ }^{46}$ Tejedo M. \& Reques R. 2003. Evaluación de los efectos del vertido tóxico de las mina sde Aznalcóllar obre la comunidade de anfíbios del rio Guadiamar. Consejería del medio ambiente de la junta de Andalucía. España, Madrid

${ }^{47}$ Marques S.M., Antunes S.C., Nunes B., Gonçalves F. \& Pereira R. 2011. Antioxidant response and metal accumulation in tissues of Iberian green frogs (Pelophylax perezi) inhabiting a deactivated uranium mine. Ecotoxicol. 20: 1315-1327

${ }^{48}$ Marques S.M., Antunes S.C., Pissara H., Pereira M.L., Gonçalves F. \& Pereira R. 2009. Histopathological changes and erythrocytic nuclear abnormalities in Iberian green frogs (Rana perezi Seoane) from a uranium pond. Aquat. Toxicol. 91: 187-195

${ }^{49}$ Salvaterra T., Alves M.G., Pereira R., Rasteiro M.G., Carvalho R.A., Soares A.M.V.M. \& Lopes I. 2013. Biochemical and metabolic effects of a short-term exposure to nanoparticles of titanium silicate in tadpoles of Pelophylax perezi. Aquat. Toxicol. 128/129: 190-192

${ }^{50}$ Martins D., Monteiro M.S., Soares A.M.V.M. \& Quintaneiro C. 2017. Effects of 4-MBC and triclosan in embryos of the frog Pelophylax perezi. Chemosphere 178: 325-332

${ }^{51}$ Santos B., Ribeiro R., Domingues I., Pereira R., Soares A.M.V.M. \& Lopes I. 2013. Salinity and copper interactive effects on Pere'z frog Pelophylax perezi. Environ. Toxicol. Chem. 32: 1864-1872

${ }^{52}$ Mingo V., Lötters S. \& Wagner N. 2016. Risk of pesticide exposure for reptile species in the European Union. Environ. Pollut. 215: 164-169

53 Wagner N., Mingo V., Schulte U. \& Lötters, S. 2015. Risk evaluation of pesticide use to protected European reptile species. Biol. Conserv. 191: 667-673

${ }^{54}$ Santos X. \& Llorente G.A. 2009. Decline of a common reptile: case study of the viperine snake Natrix maura in a Mediterranean wetland. Acta Herpetologica 4: 161-169

${ }^{55}$ Santos X., Pastor D., Llorente G.A. \& Albaigés J. 1999. Organochlorine levels in viperine snake Natrix maura carcasses from the Ebro Delta (NE Spain): sexual and size-related differences. Chemosphere 39: 2641-2650 